\title{
Correction to: Reliability of Therapist Effects in Practice-Based Psychotherapy Research: A Guide for the Planning of Future Studies
}

\author{
Anne-Katharina Schiefele ${ }^{1}$. Wolfgang Lutz ${ }^{1} \cdot$ Michael Barkham $^{2}$. Julian Rubel ${ }^{1}$. Jan Böhnke ${ }^{3}$. Jaime Delgadillo ${ }^{4}$. \\ Mark Kopta $^{5} \cdot$ Dietmar Schulte $^{6} \cdot$ David Saxon $^{2} \cdot$ Stevan L. Nielsen $^{7} \cdot$ Michael J. Lambert $^{7}$
}

Published online: 31 July 2018

○) Springer Science+Business Media, LLC, part of Springer Nature 2018

\section{Correction to: \\ Administration and Policy in Mental Health and Mental Health Services Research (2017) 44:598-613 https://doi.org/10.1007/s10488-016-0736-3}

The original version of this article unfortunately contained a mistake. In Results section, under the heading the "Application", CI difference values were incorrect in one of the sentences. The corrected sentence is given below.

"In this case, Fig. 2 indicates that 10 therapists at level 2 is not recommended, as the CI exceeds $4 \%$ (CI difference $=19.22 \%$; Table 3 ), thereby yielding an unreliable estimation".

The original article can be found online at https://doi.org/10.1007/ s10488-016-0736-3.

Anne-Katharina Schiefele

schiefele@uni-trier.de

1 Clinical Psychology and Psychotherapy, Department of Psychology, University of Trier, 54286 Trier, Germany

2 University of Sheffield, Sheffield, UK

3 Mental Health and Addiction Research Group, Hull York Medical School \& Department of Health Sciences, University of York, Heslington, UK

4 Leeds Community Healthcare NHS Trust and Department of Health Sciences, University of York, Heslington, UK

5 University of Evansville, Evansville, UK

6 Ruhr-Universität Bochum, Bochum, Germany

7 Brigham Young University, Provo, USA 